\title{
MedChemComm
}

Check for updates

Cite this: Med. Chem. Commun., 2019, 10, 1900

Received 23rd May 2019,

Accepted 15th August 2019

DOI: $10.1039 / c 9 m d 00291 j$

rsc.li/medchemcomm

\section{Structural modification of azolylacryloyl derivatives yields a novel class of covalent modifiers of hemoglobin as potential antisickling agents}

\author{
A. M. Omar, ${ }^{\star a b}$ T. David, ${ }^{C}$ P. P. Pagare, ${ }^{c}$ M. S. Ghatge, ${ }^{c}$ Q. Chen, ${ }^{d}$ A. Mehta, ${ }^{c}$ \\ Y. Zhang, ${ }^{c}$ O. Abdulmalik, ${ }^{d}$ A. H. Naghi, ${ }^{a}$ M. E. El-Araby ${ }^{a}$ and M. K. Safo iD*c
}

\begin{abstract}
The intracellular polymerization and the concomitant sickling processes, central to the pathology of sickle cell disease, can be mitigated by increasing the oxygen affinity of sickle hemoglobin ( $\mathrm{HbS}$ ). Attempts to develop azolylacryloyl derivatives to covalently interact with $\beta$ Cys 93 and destabilize the low- $\mathrm{O}_{2}$-affinity $\mathrm{T}$-state (deoxygenated) $\mathrm{HbS}$ to the polymer resistant high- $\mathrm{O}_{2}$-affinity $\mathrm{R}$-state (liganded) HbS were only partially successful. This was likely due to the azolylacryloyls carboxylate moiety directing the compounds to also bind in the central water cavity of deoxygenated $\mathrm{Hb}$ and stabilizing the T-state. We now report a second generation of KAUS compounds (KAUS-28, KAUS-33, KAUS-38, and KAUS-39) without the carboxylate moiety designed to bind exclusively to $\beta$ Cys93. As expected, the compounds showed reactivity with both free amino acid L-Cys and the $\mathrm{Hb} \beta$ Cys93. At $2 \mathrm{mM}$ concentrations, the compounds demonstrated increased $\mathrm{Hb}$ affinity for oxygen (6\% to $15 \%$ ) in vitro, while the previously reported imidazolylacryloyl carboxylate derivative, KAUS-15 only showed $4.5 \%$ increase. The increased $\mathrm{O}_{2}$ affinity effects were sustained through the experimental period of $12 \mathrm{~h}$ for KAUS-28, KAUS-33, and KAUS-38, suggesting conserved pharmacokinetic profiles. When incubated at $2 \mathrm{mM}$ with red blood cells from patients with homozygous SS, the compounds inhibited erythrocyte sickling by $5 \%$ to $9 \%$, respectively in correlation with the increase $\mathrm{Hb}-\mathrm{O}_{2}$ affinity. These values compare to $2 \%$ for KAUS-15. When tested with healthy mice, KAUS-38 showed very low toxicity.
\end{abstract}

\section{Introduction}

Sickle cell disease (SCD) is the most common inherited hematologic disorder, affecting many areas in the world. The intracellular sickling process, central to the pathology of sickle cell disease can be mitigated by increasing the oxygen affinity of sickle hemoglobin (HbS). ${ }^{1-3}$ Aromatic aldehydes exhibit these pharmacologic properties by stabilizing the relaxed state of $\mathrm{Hb}$ (R2-state) and increase $\mathrm{Hb}$ affinity for oxygen via a Schiffbase interaction with the N-terminal $\alpha$ Val1 nitrogen, and through several inter-subunit mediated interactions. ${ }^{1-4} \mathrm{Sev}^{-}$ eral aromatic aldehydes have been studied in the clinic for

\footnotetext{
${ }^{a}$ Department of Pharmaceutical Chemistry, Faculty of Pharmacy, King Abdulaziz University, Alsulaymanyah, Jeddah 21589, Saudi Arabia.

E-mail: asmansour@kau.edu.sa

${ }^{b}$ Department of Pharmaceutical Chemistry, Faculty of Pharmacy, Al-Azhar University, Cairo 11884, Egypt

${ }^{c}$ Department of Medicinal Chemistry, School of Pharmacy and Institute for Structural Biology, Drug Discovery and Development, Virginia Commonwealth University, Richmond, VA 23219, USA. E-mail: msafo@vcu.edu

${ }^{d}$ Division of Hematology, The Children's Hospital of Philadelphia, PA 19104, USA
}

the treatment of SCD, with one such compound, GBT440 (Voxelotor) currently undergoing phase III studies. ${ }^{4}$ With very few exceptions, e.g. GBT440, a major drawback of aromatic aldehydes as therapeutic agents is poor pharmacokinetic properties due to significant and rapid metabolic oxidation of the aldehyde moiety into the corresponding inactive functional metabolites. ${ }^{5-8}$ Hence, efforts are being made to replace the aldehyde group with different metabolically stable electrophiles. $^{9-12}$ We recently studied several such covalent modifiers for their antisickling activity. ${ }^{11}$ The compounds were expected to increase oxygen affinity of $\mathrm{Hb}$ via a Michael addition reaction between their $\beta$-unsaturated carbon and the sulfur atom of $\beta$ Cys93 (Scheme 1), disrupting a T-state stabilization salt-bridge interaction, and shifting the allosteric equilibrium to the R-state. ${ }^{11}$ Unfortunately, the compounds, as exemplified by KAUS-15 (Fig. 1), only showed weak or no effect on $\mathrm{Hb}$ oxygen affinity, explaining their weak antisickling activities. Solution studies suggest that the compounds bind predominantly to free $\mathrm{L}$-Cys and $\mathrm{Hb} \beta \mathrm{Cys} 93$. Crystallographic studies also showed a second binding to the $\mathrm{N}$-terminal $\alpha$ Val1 at the central water cavity of deoxygenated $\mathrm{Hb}$, with their 

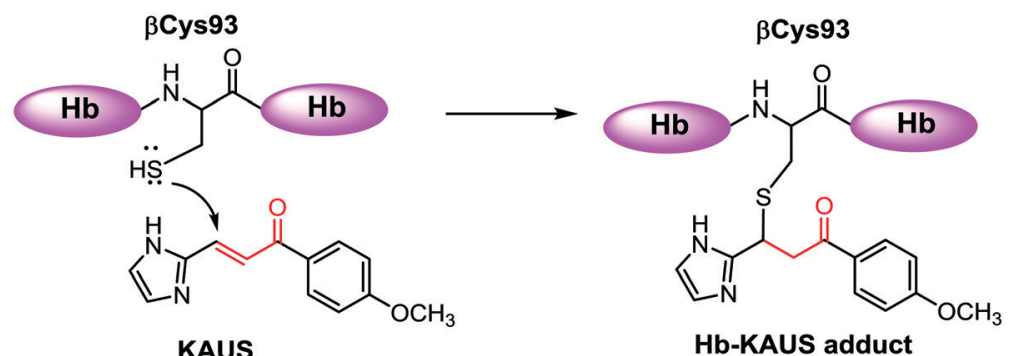

Scheme 1 Schematic representation of the Michael addition reaction between the $\beta$-unsaturated carbon of Michael addition compound and the $\beta C y s 93$ sulfur of hemoglobin.

carboxylate moieties involved in protein interactions that stabilize the T-state $\mathrm{Hb}$, explaining the observed biological effect. ${ }^{11}$ This study reports a second generation of several KAUS molecules without the carboxylate moiety, and expected to bind exclusively to $\beta$ Cys93. The compounds were studied for their reactivity with $\beta$ Cys93 of $\mathrm{Hb}$ and free $\mathrm{L}$-Cys, in vitro effects on $\mathrm{Hb}-\mathrm{O}_{2}$ affinity and sickle $\mathrm{RBC}$ morphology, as well as acute toxicity with mice.

\section{Materials and methods}

\section{General}

All melting points were uncorrected and measured using the capillary melting point instrument BI 9100 (Barnstead Electrothermal, UK). ${ }^{1} \mathrm{H}$ NMR spectra were determined on an AVANCE-III $600 \mathrm{MHz}$ and AVANCE-III HD $850 \mathrm{MHz}$ spectrometers (Bruker, Germany), and chemical shifts are expressed as ppm against TMS as an internal standard (King Fahd Center for Medical Research and Faculty of Science, King Abdulaziz University, Jeddah, Saudi Arabia). LC/MS analyses were performed on an Agilent 6320 Ion Trap HPLC-ESI-MS/ DAD (Santa Clara, CA, USA) with the following settings: the analytes were separated using a Macherey-Nagel NucleodurC18 column (150 mm length $\times 4.6 \mathrm{~mm}$ i.d., $5 \mu \mathrm{m}$ ) (MachereyNagel GMBH \& Co. KG, Duren, Germany). Mobile phase; isocratic elution using a mixture of acetonitrile and 0.01 formic<smiles>O=C(O)CCCOc1ccc(C(=O)C=Cc2ncc[nH]2)cc1Cl</smiles><smiles>O=C(/C=C/c1ncc[nH]1)c1ccccc1</smiles><smiles>COc1ccc(C(=O)/C=C/c2ncc[nH]2)cc1</smiles>

KAUS-38

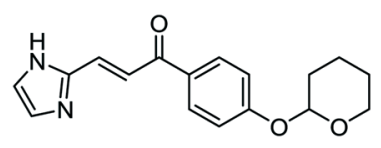

KAUS-33<smiles>COc1ccc(C(=O)/C=C/c2ncc[nH]2)cc1OC</smiles>

KAUS-39
Fig. 1 Azolylacryloyl derivatives without carboxylate functional group. acid in water $(80: 20, \mathrm{v} / \mathrm{v})$. The flow rate was $0.4 \mathrm{~mL} \mathrm{~min}^{-1}$; total run time $=20 \mathrm{~min}$. Purities are reported according to percentage of Peak Areas at wavelength $280 \mathrm{~nm}$. According to LC/MS analyses, all compounds in this study were confirmed to have $95 \%$ purity or higher. High-resolution mass spectrometry (HRMS) was performed in the Faculty of Science, King Abdulaziz University on Impact II $^{\mathrm{TM}} \mathrm{Q}-\mathrm{TOF}$ spectrometer (Bruker, Germany).

De-identified, leftover EDTA venous sickle whole blood samples from patients with SCD who visited The Children's Hospital of Philadelphia for routine clinic visits, were obtained after informed consent. Normal whole blood were obtained from adult donors at the Virginia Commonwealth University after informed consent.

Synthesis of $(E)-3-(1 H$-imidazol-2-yl)-1-phenylprop-2-en-1-one (KAUS-28)

$1 H$-Imidazole-2-carbaldehyde $(2.88 \mathrm{~g}, \quad 30 \mathrm{mmol})$ and acetophenone ( $4.32 \mathrm{~g}, 4.2 \mathrm{~mL}, 36 \mathrm{mmol})$ were dissolved in 40 $\mathrm{ml}$ of ethanol, and a $1 \mathrm{~N}$ aqueous solution $(40 \mathrm{ml})$ of sodium hydroxide was added to the solution. The mixture was stirred at room temperature for $8 \mathrm{~h} .1 \mathrm{~N}$ hydrochloric acid $(40 \mathrm{ml})$ was added to the resultant reaction mixture to conduct the extraction with chloroform. An organic layer was washed with saturated brine, dried and then concentrated under reduced pressure. The resultant residue was subjected to column chromatography on silica gel. Crystals obtained from a fraction eluted with $1 \%(\mathrm{v} / \mathrm{v})$ methanol-chloroform were recrystallized from ethyl acetate to obtain the titled compound as off-white powder $(2.1 \mathrm{~g}, 60 \%)$. MP: $182-184{ }^{\circ} \mathrm{C} .{ }^{1} \mathrm{H}$ NMR (850 MHz, DMSO- $d_{6}$ ) $\delta$ ppm 7.25-7.38 (m, 1H) 7.51 (d, $J=15.57 \mathrm{~Hz}, 1 \mathrm{H}) 7.60(\mathrm{t}, J=7.79 \mathrm{~Hz}, 2 \mathrm{H}) 7.69(\mathrm{t}, J=7.27 \mathrm{~Hz}$, 1H) 7.87 (d, $J=15.57 \mathrm{~Hz}, 1 \mathrm{H}) 8.05$ (d, $J=7.27 \mathrm{~Hz}, 2 \mathrm{H}) .{ }^{13} \mathrm{C}$ NMR (151 MHz, DMSO- $\left.d_{6}\right) \delta 188.8,143.4,137.4,133.2,132.0$, 128.9, 128.2, 121.1. HRMS (ESI) calculated $\mathrm{m} / \mathrm{z}$ 199.0866; found $m / z 199.0850(\mathrm{M}+)$.

Synthesis of $(E)-3-(1 H$-imidazol-2-yl)-1-(4-((tetrahydro- $2 H$ pyran-2-yl)oxy)phenyl)prop-2-en-1-one (KAUS-33)

1H-Imidazole-2-carbaldehyde and 1-(4-((tetrahydro-2H-pyran-2yl)oxy)phenyl)ethan-1-one were reacted to afford a white solid (4.9 g, 51\%) from (E)-3-(1H-imidazol-2-yl)-1-(4-((tetrahydro- $2 H$ pyran-2-yl)oxy)phenyl)prop-2-en-1-one (KAUS-33) by the same 
procedure described above for the synthesis of KAUS-28. MP: 186-187 ${ }^{\circ} \mathrm{C}$. ${ }^{1} \mathrm{H}$ NMR (850 MHz, DMSO- $d_{6}$ ) $\delta$ ppm 1.52-1.57 $(\mathrm{m}, 1 \mathrm{H})$ 1.58-1.68 (m, 2H) 1.76-1.80 (m, 1H) 1.83-1.92 (m, 2H) $3.60(\mathrm{dt}, J=11.29,4.22 \mathrm{~Hz}, 1 \mathrm{H}) 3.72-3.76(\mathrm{~m}, 1 \mathrm{H}) 5.66(\mathrm{t}$, $J=3.37 \mathrm{~Hz}, 1 \mathrm{H}) 7.19-7.22$ (m, 2H) 7.43 (br. s., 1H) 7.47 (d, $J=$ $15.57 \mathrm{~Hz}, 1 \mathrm{H}) 7.87$ (d, $J=15.57 \mathrm{~Hz}, 1 \mathrm{H})$ 8.03-8.06 (m, 1H) 12.82 (br. s., $1 \mathrm{H}) .{ }^{13} \mathrm{C}$ NMR (151 MHz, DMSO- $\left.d_{6}\right) \delta$ 187.0, 160.5 , 143.5, 131.3, 131.1, 130.9, 130.4, 130.0, 121.1, 119.9, 116.2, 115.5, 95.4, 61.7, 61.6, 29.5, 24.5, 18.3. HRMS (ESI) calculated $\mathrm{m} / \mathrm{z}$ 299.1390; found $\mathrm{m} / \mathrm{z} 299.1337$ (M+).

Synthesis of $(E)-3-(1 H$-imidazol-2-yl)-1-(4-methoxyphenyl)prop2-en-1-one (KAUS-38)

This compound was prepared following the procedure described above for the synthesis of the similar analogue KAUS28 and was obtained as a white solid (3.6 g, 53\%). MP: 193$194{ }^{\circ} \mathrm{C} .{ }^{1} \mathrm{H}$ NMR (850 MHz, DMSO- $\left.d_{6}\right) \delta$ ppm $3.88(\mathrm{~s}, 3 \mathrm{H}$ ) 7.11-7.14 (m, 1H) 7.18 (br. s., 1H) 7.43 (br. s., 1H) 7.47 (d, $J=$ $15.57 \mathrm{~Hz}, 1 \mathrm{H}) 7.89$ (d, $J=15.57 \mathrm{~Hz}, 1 \mathrm{H})$ 8.04-8.08 (m, 1H) 12.82 (br. s., $1 \mathrm{H})$.

Synthesis of (E)-1-(3,4-dimethoxyphenyl)-3-(1H-imidazol-2yl)prop-2-en-1-one (KAUS-39)

This compound was prepared following the procedure described above for the synthesis of the similar analogue KAUS28 and was obtained as an off-white solid (2.7 g, 37\%). MP: 222-223 ${ }^{\circ} \mathrm{C} .{ }^{1} \mathrm{H}$ NMR (400 MHz, DMSO- $\left.d_{6}\right) \delta$ ppm $3.88(\mathrm{~s}, 3 \mathrm{H})$ $3.90(\mathrm{~s}, 3 \mathrm{H}) 7.16(\mathrm{~d}, J=8.53 \mathrm{~Hz}, 1 \mathrm{H}) 7.20-7.34(\mathrm{~m}, 1 \mathrm{H}) 7.37$ (br. s., 1H) 7.50 (d, $J=15.56 \mathrm{~Hz}, 1 \mathrm{H}) 7.58(\mathrm{~d}, J=2.01 \mathrm{~Hz}, 1 \mathrm{H})$ $7.78(\mathrm{dd}, J=8.53,2.01 \mathrm{~Hz}, 1 \mathrm{H}) 7.90(\mathrm{~d}, J=15.56 \mathrm{~Hz}, 1 \mathrm{H})$.

Oxygen equilibrium curve (OEC) studies. The ability of the compounds, KAUS-28, KAUS-33, KAUS-38, and KAUS-39 (1 $\mathrm{mM}$ and $2 \mathrm{mM}$ final concentration) to increase hemoglobin affinity for oxygen was tested with normal whole blood (hematocrit of $20 \%$ ) with $2 \mathrm{~h}$ incubation at $37^{\circ} \mathrm{C}$ as previously reported. ${ }^{11,13,14}$ The studies were performed at least in triplicates. Time dependent studies were also conducted with whole blood at $2 \mathrm{mM}$ concentration, with incubation for up to $24 \mathrm{~h}$ at $37^{\circ} \mathrm{C}$. Aliquot samples were tested at 1, 2, 4, 8, and $24 \mathrm{~h}$, and DMSO was used as control. KAUS-15 was used as a control.

Antisickling studies. All compounds, KAUS-28, KAUS-33, KAUS-38, KAUS-39, and the control KAUS-15 were tested for their abilities to prevent RBC sickling under hypoxic condition following previously reported assay. ${ }^{11,13,14}$ Briefly SS cells were suspended in Hemox buffer (TCS Scientific Corp, Southampton, PA), pH 7.4, supplemented with $10 \mathrm{mM}$ glucose and $0.2 \%$ bovine serum albumin. The solution was incubated under air in the absence (control) or presence of $2 \mathrm{mM}$ concentration of test compound at $37^{\circ} \mathrm{C}$ for $1 \mathrm{~h}$. Following, the suspension was incubated under hypoxic condition (4\% oxygen/96\% nitrogen) at $37{ }^{\circ} \mathrm{C}$ for $2 \mathrm{~h}$. The suspension was fixed with $2 \%$ glutaraldehyde solution without exposure to air and then subjected to microscopic morphological analysis as previously reported. ${ }^{13}$
Reactivity of KAUS compounds toward free amino acid, L-cysteine

The KAUS compounds were expected to covalently bind to $\mathrm{Hb}$ through a Michael addition reaction with the $\beta$ Cys93 to affect their allosteric and antisickling activities. We therefore investigated L-Cys conjugates with KAUS-28, KAUS-33, KAUS-38 and KAUS-39 using UPLC-MS analysis as previously described $^{11}$ with an Acquity H-Class UPLC, which is connected to a PDA detector and an Acquity TQD detector. The column used was an Acquity UPLC BEH C18 $1.7 \mu \mathrm{m}, 2.1 \times 50 \mathrm{~mm}$, with a Vanguard pre-column attached. Solvent A consisted of water with $0.02 \%$ formic acid, while solvent B consisted of $90: 10$ acetonitrile: water with $0.02 \%$ formic acid. A gradient run was performed such that solvent B was increased from $0 \% \mathrm{~B}$ to $100 \% \mathrm{~B}$ from time $0-5 \mathrm{~min}$, followed by 3 minute wash at $100 \% \mathrm{~B}$ and then a return and re-equilibration at $100 \% \mathrm{~A}$ in the next $4 \mathrm{~min}$. The flow rate was maintained at $0.5 \mathrm{ml} \mathrm{min}^{-1}$ throughout the run. $2 \mu \mathrm{L}$ of sample was injected per run. The eluent of the column was connected to a PDA UV detector, which scanned from 220-350 $\mathrm{nm}$ and showed a $2 \mathrm{D}$ channel of $280 \mathrm{~nm}$. The eluent was then introduced into the TQD detector. The TQD detector was set at positive ionization mode with a capillary voltage of $3.20 \mathrm{kV}$, cone voltage of $20 \mathrm{~V}$, extractor voltage of $1 \mathrm{~V}$, and RF lens voltage of $0.1 \mathrm{~V}$. The source temperature was set at $150{ }^{\circ} \mathrm{C}$, while the desolvation temperature was set at $350{ }^{\circ} \mathrm{C}$ and the desolvation and cone gas flows were set at 650 and $50 \mathrm{~L} \mathrm{~h}^{-1}$ respectively. Scans were made from $100-700 \mathrm{~m} / \mathrm{z}$ with scan duration of 0.5 seconds to obtain mass spectra at different time points.

\section{Reactivity of KAUS compounds toward $\beta$ Cys93 of $\mathrm{Hb}$}

The accessible sulfhydryl groups in $\mathrm{Hb}$, and their reactivity with the KAUS compounds, were quantified by observing the results of the disulfide exchange reaction of the thiols of $\beta$ Cys93 and DTNB at $412 \mathrm{~nm}\left(\varepsilon=14150 \mathrm{M}^{-1} \mathrm{~cm}^{-1}\right){ }^{11} \mathrm{An}$ aqueous solution of $\mathrm{Hb}(50 \mu \mathrm{M}$ in PBS) was mixed with KAUS-28, KAUS-38, KAUS-39 and the positive control KAUS15 ( $2 \mathrm{mM}$ final concentration) in a final volume of $500 \mu \mathrm{L}$. The mixture was incubated at room temperature for $2 \mathrm{~h}$ or $16 \mathrm{~h}$. The mixture was initially centrifuged at $10000 \mathrm{rpm}$ for $10 \mathrm{~min}$ at $4{ }^{\circ} \mathrm{C}$ to settle any precipitate that may have formed during the reaction. The supernatant was transferred to a microfiltration centrifugal tube (MWCO $10 \mathrm{kDa}$ ) and was centrifuged to separate $\mathrm{Hb}$ from excess reagents at $7000 \mathrm{rpm}$ for $30 \mathrm{~min}$ at $4{ }^{\circ} \mathrm{C}$. $\mathrm{Hb}$ was washed with PBS and centrifuged again to a final volume of $100 \mu \mathrm{L}$. The washed $\mathrm{Hb}$ was stored at $4{ }^{\circ} \mathrm{C} .25 \mu \mathrm{L}$ of each $\mathrm{Hb}$ solution was added to $0.1 \mathrm{M}$ potassium phosphate buffer $(475 \mu \mathrm{L})$ at $\mathrm{pH} 8.0$ and incubated at $25{ }^{\circ} \mathrm{C}$ for $1 \mathrm{~h}$ (non-DTNB control samples). Another $25 \mu \mathrm{L}$ of each $\mathrm{Hb}$ solution was added to the phosphate buffer $(465 \mu \mathrm{L})$ with $10 \mu \mathrm{L}$ of DTNB (10 mM in buffer) and incubated at $25{ }^{\circ} \mathrm{C}$ for $1 \mathrm{~h}$. Before centrifuging the non-DTNB control samples, the absorbance of each sample was taken at $576 \mathrm{~nm}$ to determine 


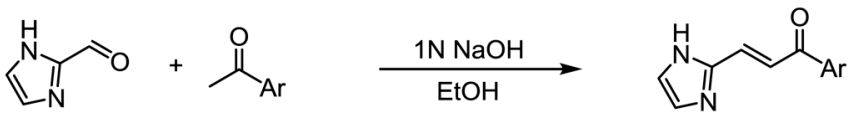

$\begin{aligned} \mathrm{Ar}= & \text { Phenyl (KAUS-28) } \\ & \text { 4-methoxyphenyl (KAUS-38) }\end{aligned}$

4-((tetrahydro-2H-pyran-2-yl)oxy)phenyl (KAUS-33)

3,4-dimethoxyphenyl (KAUS-39)

Scheme 2

the concentration of $\mathrm{Hb}$ and quantify the $\beta \mathrm{Cys} 93$ concentration in each sample. Both sets of tubes were centrifuged using different centrifugal filters (7000 rpm, $20 \mathrm{~min}, 4^{\circ} \mathrm{C}$ ) to collect the yellow filtrate (2-nitrobenzoate), which was quantified by measuring absorbance at $412 \mathrm{~nm}$.

\section{Determination of acute oral toxicity $\left(\mathbf{L D}_{50}\right)$}

The experiment was conducted on 9 healthy Swiss albino mice (males and females) weighing $22-27 \mathrm{~g}$ and aged 8 to 10 weeks obtained from the Animal Station, Pharmacology Dept., Faculty of Pharmacy, King Abdulaziz University, Jeddah. All animals were kept at the regulated temperature (average $23^{\circ} \mathrm{C}$ ), air quality (central air conditioning) and light (12 h light/dark cycles). Animals were provided free access to food pellets ad libitum and water. All animal procedures were performed in accordance with the Guidelines for Care and Use of Laboratory Animals of King Abdulaziz University and approved by the Animal Ethics Committee of Research on living Creatures in the Kingdom of Saudi Arabia. Animals were humanely treated according to international and scientific principles. KAUS-38 of purity $95 \%$ or more (LC/MS) was prepared as $10 \%$ suspension in water containing $0.5 \%$ tween 80 . Mice $(n=3)$ were treated with an oral starting dose of KAUS38 of $2000 \mathrm{mg}$ per $\mathrm{kg}$ body weight using a stainless-steel gouge gavage needle. On day 2, same steps, also using an oral dose of KAUS-38 of $2000 \mathrm{mg}$ per $\mathrm{kg}$ body weight were repeated on a second group of mice $(n=3)$. On day 3 , an oral dose of KAUS-38 of $5000 \mathrm{mg}$ per $\mathrm{kg}$ body weight was administrated on a third group of mice $(n=3)$. Following each dose, the animals were observed for $24 \mathrm{~h}$ for any signs of toxicity including mortality.

\section{Result and discussion}

Scheme 2 was followed for the synthesis of KAUS-28, KAUS-33, KAUS-38 and KAUS-39 (Fig. 1). The control, KAUS-15 was synthesized as previously published. ${ }^{11}$ For the synthesis, 2-imidazole carbaldehyde $(2.88 \mathrm{~g}, 30 \mathrm{mmol})$ and substituted acetophenone (36 mmol) were dissolved in $40 \mathrm{ml}$ of ethanol, and a $1 \mathrm{~N}$ aqueous solution $(40 \mathrm{ml})$ of sodium hydroxide was added to the solution. The mixture was stirred at room temperature for $8 \mathrm{~h} .1 \mathrm{~N}$ hydrochloric acid $(40 \mathrm{ml})$ was added to the resultant reaction mixture to conduct the extraction with chloroform. The organic layer was washed with saturated brine, dried and then concentrated under reduced pressure. The resultant residue was subjected to column chromatography on silica gel. Product obtained from a fraction eluted with $1 \%$ (v/v) methanol-chloroform was recrystallized from ethyl acetate.

\section{Compounds react with both free $\mathrm{L}-\mathrm{Cys}$ and $\beta \mathrm{Cys} 93$ of $\mathrm{Hb}$}

UPLC-MS analysis of the reaction between the compounds and free L-Cys (that was incubated for $3 \mathrm{~h}$ ) is shown in Table 1 . KAUS-38 was the most reactive $(77 \%)$, followed by KAUS-33 (55\%), KAUS-39 (54\%), while KAUS-28 showed the least reactivity $(20 \%)$. As previously reported, solution-based sulfhydryl assay identified only two accessible thiols, out of the six present in $\mathrm{Hb}$, consistent with the two $\beta$ Cys93 as the only solvent accessible and reactive cysteine. ${ }^{11}$ The reactivity of the KAUS compounds (KAUS-28, KAUS-38 and KAUS-39) with these accessible sulfhydryl groups in $\mathrm{Hb}$ was quantified by the disulfide exchange reaction of the thiols of $\beta$ Cys93 in $\mathrm{Hb}$ and DTNB at $412 \mathrm{~nm}$. All three compounds showed 10\% reactivity with $\beta$ Cys93 at $2 \mathrm{~h}$ incubation, which increased to $37 \%$ for KAUS-38 and $20 \%$ for both KAUS-28 and KAUS-39

Table 1 UPLC-MS measurements of relative ratio of azolylacryloyl compounds and their adduct products with L-cysteine

\begin{tabular}{|c|c|c|c|c|c|c|}
\hline Amino acid & Compound & Peak & $\mathrm{RT}^{a}(\min )$ & Max. $m / z$ & Area & $\%$ compound $^{b}$ or adduct \\
\hline \multirow[t]{8}{*}{ Cysteine } & \multirow[t]{2}{*}{ KAUS-28 } & Compound & 2.09 & 199.1 & 3997 & 80.4 \\
\hline & & Adduct & 1.61 & 320.2 & 972 & 19.6 \\
\hline & \multirow[t]{2}{*}{ KAUS- $33^{c}$} & Compound & 1.77 & $215.1^{c}$ & 5238 & 45.1 \\
\hline & & Adduct & 1.27 & $336.2^{c}$ & 6387 & 54.9 \\
\hline & \multirow[t]{2}{*}{ KAUS-38 } & Compound & 2.21 & 229.1 & 2528 & 23.0 \\
\hline & & Adduct & 1.81 & 350.2 & 8450 & 77.0 \\
\hline & \multirow[t]{2}{*}{ KAUS-39 } & Compound & 2.12 & 259.1 & 3921 & 46.3 \\
\hline & & Adduct & 1.74 & 380.2 & 4555 & 53.7 \\
\hline
\end{tabular}

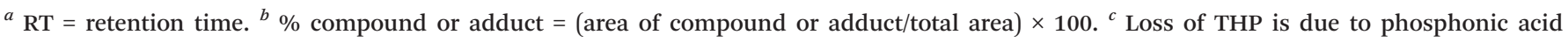
treatment. 
Table 2 Relative ratios of free thiol from $\beta$ Cys 93 in $\mathrm{Hb}$ and their adduct products with azolylacryloyl compounds

\begin{tabular}{llll}
\hline Compound & $\begin{array}{l}\text { Incubation } \\
\text { time }(\mathrm{h})\end{array}$ & $\begin{array}{l}\text { \% available }- \text { SH from } \\
\text { two } \beta \text { Cys93 }\end{array}$ & $\begin{array}{l}\% \text { adduct } \\
\text { formed }\end{array}$ \\
\hline KAUS-15 & 2 & $89 \pm 4$ & 11 \\
& 16 & $70 \pm 5$ & 30 \\
KAUS-28 & 2 & $90 \pm 9$ & 10 \\
& 16 & $79 \pm 1$ & 21 \\
KAUS-38 & 2 & $89 \pm 4$ & 11 \\
& 16 & $63 \pm 5$ & 37 \\
KAUS-39 & 2 & $91 \pm 5$ & 9 \\
& 16 & $80 \pm 3$ & 20
\end{tabular}

Values are mean of quadruplet measurements \pm SD. \% adduct formed $=100-($ available - SH from two $\beta$ Cys93 $)$.

after $16 \mathrm{~h}$ (Table 2). The positive control KAUS-15 shows comparative values of $10 \%$ and $30 \%$ at $2 \mathrm{~h}$ and $16 \mathrm{~h}$, respectively. It is also apparent that the KAUS compounds are more reactive toward free Cys than $\beta$ Cys93 of $\mathrm{Hb}$, which could be due to steric constraint to reacting with the partially buried $\beta$ Cys93.

\section{Compounds increased $\mathrm{Hb}$ affinity for oxygen with sustained effect}

The compounds were subjected to oxygen equilibrium studies using 3-point tonometry to assess $P_{50}$ shifts or increase in $\mathrm{Hb}$ oxygen affinity. $P_{50}$ is the oxygen pressure at which hemoglobin is $50 \%$ saturated with oxygen. All compounds increased $\mathrm{Hb}$ affinity for oxygen, showing a left shift in the OEC curve, when tested with normal whole blood (Fig. 2). The compounds also showed concentration-dependent OEC effect. In whole blood KAUS-33 showed the most potent effect (9.9 and $15.2 \%$ at $1 \mathrm{mM}$ and $2 \mathrm{mM}$, respectively), followed by KAUS-38 (8.2 and 11.8\%), then KAUS-28 (7.0 and 11.3\%), and KAUS-39 ( 6.5\%) (Fig. 3). These values compare with the positive control, KAUS-15 at 1.9 and $4.5 \%$, respectively, clearly indicating improvement in the allosteric properties of these new compounds. Unlike KAUS-15, these compounds do not contain carboxylate function, and therefore we attribute the increased potency to the removal of the carboxylate moiety, which is expected to exclude binding to the central water cavity of deoxygenated $\mathrm{Hb}$ to stabilize the $\mathrm{T}$-state.

Time-dependent OEC studies showed that at $2 \mathrm{mM}$ concentration, KAUS-28, KAUS-33, and KAUS-38 sustained their

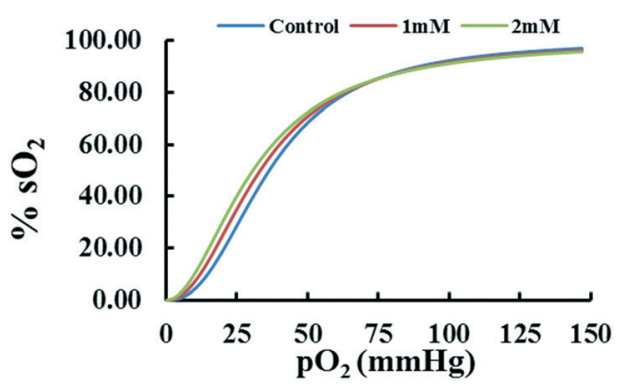

Fig. 2 Representative OEC (KAUS-38) showing a dose-dependent increase in $\mathrm{Hb}$ oxygen affinity. activity throughout the $24 \mathrm{~h}$ experiment, while KAUS-39 started to decline after $8 \mathrm{~h}$ (Fig. 4). A similar activity decline was also observed with KAUS-15. It is also interesting to point out that KAUS-39, among the five compounds studied (including KAUS-15) showed the slowest onset. The apparent metabolic stability of these compounds' contrasts with most aromatic aldehyde antisickling agents, which suffer from rapid metabolism and thus have short pharmacologic activities. Thus, as proposed, the current azolylacryloyl derivatives appear to have superior in vitro allosteric effect than the carboxylate-containing azolylacryloyl, as well as are metabolically stable than some of the previously studied antisickling aromatic aldehydes. ${ }^{5,7,13,15}$ The four KAUS compounds differ by having varying, or no substitutions on the phenyl ring. However, it does not appear that the size of the substitution correlates with the allosteric activities of these compounds, suggesting that the substituted phenyl ring may not be important in binding.

Compounds demonstrated mild in vitro antisickling effect on blood samples from subjects with homozygous sickle cell disease

Compounds that increase the oxygen affinity of $\mathrm{Hb}$ are expected to inhibit $\mathrm{RBC}$ sickling as high- $\mathrm{O}_{2}$-affinity sickle $\mathrm{Hb}$ does not polymerize. ${ }^{2,14,16}$ As expected from their ability to increase the oxygen affinity of $\mathrm{Hb}$, all the KAUS compounds inhibited erythrocyte sickling, with KAUS-38 showing the most potent effect of $9 \%$, followed by KAUS-33 and KAUS 28 (7\%), then KAUS-39 (5\%), and lastly the control KAUS-15 (2\%) (Fig. 5).

\section{Compounds demonstrated low toxicity in healthy mice}

Since compounds with electrophilic properties, e.g. Michael addition are usually involved in a variety of toxic effects on mammalians, we decided to investigate the general acute toxicity of KAUS-38 by determining the in vivo lethal dose $\left(\mathrm{LD}_{50}\right)^{17}$ according to the Globally Harmonized Classification System (GHS) and following the OECD guideline 423 (modified, adopted March 23, 2006). Healthy Swiss albino mice (males and females) weighing 22-27 $\mathrm{g}$ and aged 8 to 10 weeks were divided into 3 groups ( 3 mice in each group). Group 1 and 2 were given an oral dose of $2000 \mathrm{mg}$ per $\mathrm{kg}$ body weight while group 3 was given an oral dose of $5000 \mathrm{mg}$ per $\mathrm{kg}$ body weight. Following dosing, the mice was observed for $24 \mathrm{~h}$ for any signs of toxicity, including mortality. It was observed that all mice tolerated an oral dose of $2000 \mathrm{mg} \mathrm{kg}^{-1}$ of KAUS-38, since no mice from groups 1 and 2 died after $24 \mathrm{~h}$ of drug administration. However, 2 out of the 3 mice in group 3 (given $5000 \mathrm{mg} \mathrm{kg}^{-1}$ doses) were found to be dead. This preliminary toxicity study suggests KAUS-38 to have potentially low toxicity on mammals. We note that the excipient used for the in vivo delivery were much better in solubilizing the compounds, but not appropriate for in vitro studies. The toxicity result is consistent with our published cellular study with similar Michael addition class of compounds that are show 


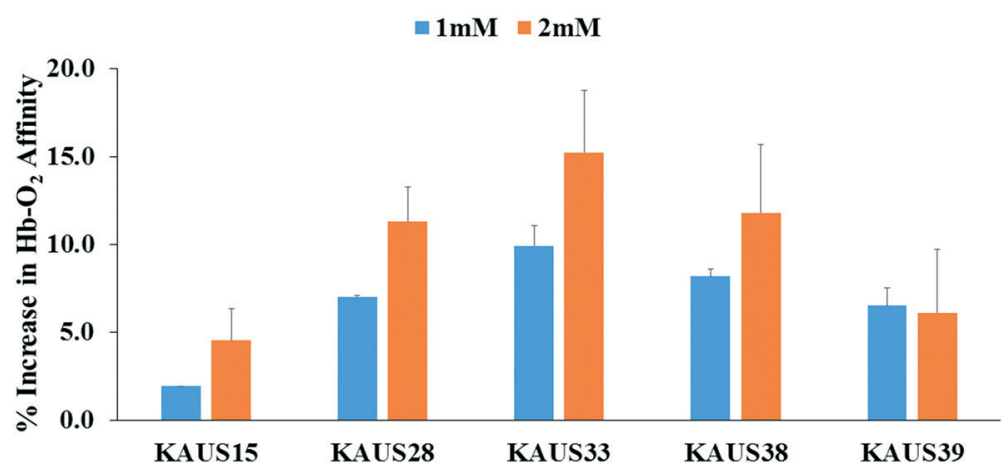

Fig. 3 Degree of shift in oxygen equilibria $\left(\Delta P_{50}\right)$ by test compounds expressed in percentage. Data reported are mean values and standard deviations; from at least three replicate experiments.

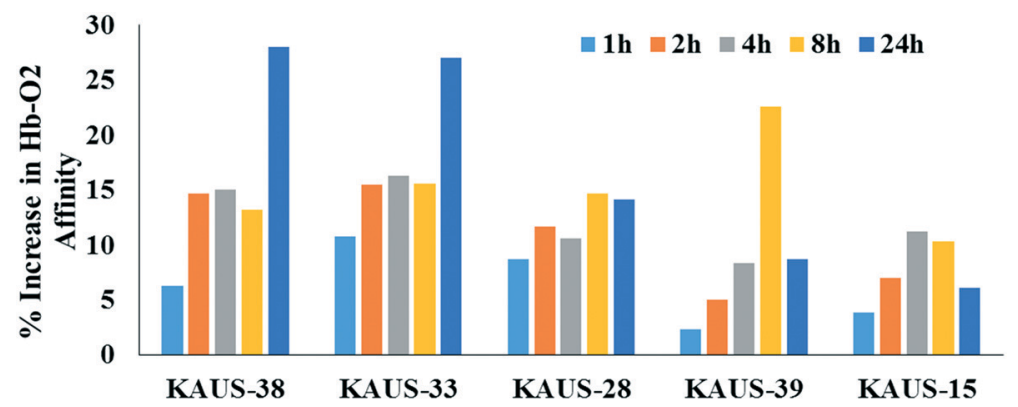

Fig. 4 Time-dependent $P_{50}$ shift of $\mathrm{Hb}$ in normal blood incubated with test compounds.

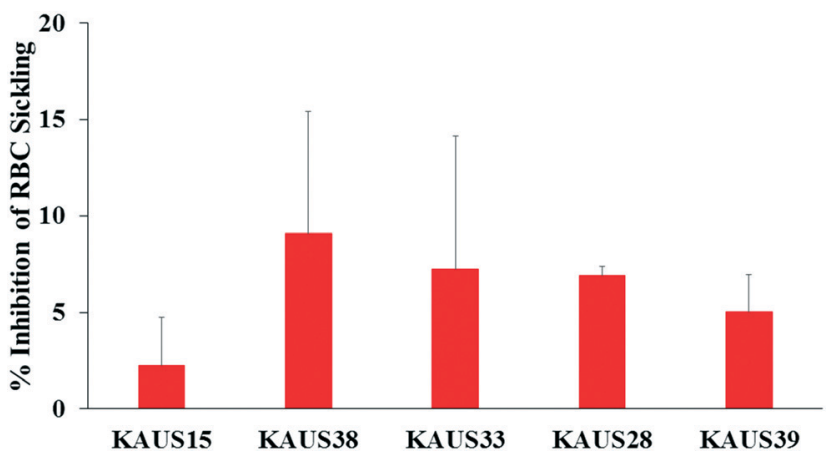

Fig. 5 Inhibition of SS cell sickling by KAUS compounds. Data reported are mean values and standard deviations; from at least three replicate experiments.

more solubility, which also showed no toxicity effect. ${ }^{11}$ Further toxicity studies are warranted for sub-chronic and chronic ranges to confirm safety of the compounds.

\section{Conclusion}

We previously developed azolylacryloyl-carboxylate compounds that we hypothesize would bind covalently to $\beta$ Cys93 of $\mathrm{Hb}$ and destabilize the $\mathrm{T}$-state to increase the protein affinity for oxygen that would translate to antisickling effects. ${ }^{11}$ These compounds, with the representative example of KAUS15 showed only marginal effect in increasing $\mathrm{Hb}$ oxygen affinity or preventing RBC sickling. ${ }^{11}$ Crystallographic studies suggested that their low functional/biological activities are in part due to the compounds binding to the central water cavity of deoxygenated $\mathrm{Hb}$ to stabilize the T-state. ${ }^{11}$ In the present study, we modified some of these compounds by removing their carboxylate groups to allow the compounds to bind preferentially at $\beta$ Cys93 and exhibit more potent OEC and/or antisickling activities. Four compounds were synthesized, and as expected exhibited improvement in vitro $\mathrm{Hb}-\mathrm{O}_{2}$ affinity and RBC sickling inhibition over KAUS-15, although not as potent as expected. Nonetheless, our findings suggest that our structural modifications are in the right direction, and establish the current non-carboxylate azolylacryloyl derivatives as a novel and potentially non-toxic promising group of anti-sickling agents, and provide proof-of-concept justifications for further structural modifications to develop candidate therapeutics for SCD.

All human experiments were performed in accordance with the Guidelines of the Institutional Review Boards (IRB) of The Children's Hospital of Philadelphia and Virginia Commonwealth University, and experiments were approved by the ethics committee at The Children's Hospital of Philadelphia and Virginia Commonwealth University, respectively. Informed consents were obtained from human participants of this study.

\section{Conflicts of interest}

The Azolylacryloyl derivatives are under consideration for patent protection. 


\section{Acknowledgements}

The authors acknowledge with thanks technical and financial support by Deanship of Scientific Research (DSR) at King Abdulaziz University, Jeddah, under grant no. (RG-1-166-39). Other financial support by NIH/NIMHD grant MD009124/ MD009124S1 (MKS). Special thanks to Professor Ashraf B. Abdel-Naim, Pharmacology and Toxicology Dept., King Abdulaziz University for valuable guidance in conducting the $\mathrm{LD}_{50}$ study.

\section{References}

1 M. K. Safo and G. J. Kato, Therapeutic strategies to alter the oxygen affinity of sickle hemoglobin, Hematol. Oncol. Clin. North Am., 2014, 28(2), 217-231.

2 M. K. Safo, M. H. Ahmed, M. S. Ghatge and T. Boyiri, Hemoglobin-ligand binding: understanding $\mathrm{Hb}$ function and allostery on atomic level, Biochim. Biophys. Acta, 2011, 1814(6), 797-809.

3 M. K. Safo and S. Bruno, in Allosteric Effectors of Hemoglobin: Past, Present and Future, Chemistry and Biochemistry of Oxygen Therapeutics, ed. A. Mozzarelli and S. Bettati, John Wiley \& Sons, Ltd, 2011, pp. 285-300, Available from: http://onlinelibrary.wiley.com/doi/10.1002/ 9781119975427.ch21/summary.

4 Study to Evaluate the Effect of GBT440 Administered Orally to Patients With Sickle Cell Disease (GBT_HOPE) - Full Text View - ClinicalTrials.gov [Internet], [Cited 2018 Mar 21], Available from: https://clinicaltrials.gov/ct2/show/NCT03036813.

5 G. G. Xu, P. P. Pagare, M. S. Ghatge, R. P. Safo, A. Gazi and Q. Chen, et al., Design, Synthesis, and Biological Evaluation of Ester and Ether Derivatives of Antisickling Agent 5-HMF for the Treatment of Sickle Cell Disease, Mol. Pharmaceutics, 2017, 14(10), 3499-3511.

6 A. Parikh and J. Venitz, Novel In Vitro Target-site Drug Disposition (TSDD)/Pharmacodynamic (PD) Model for 5-Hydroxymethylfurfural (5-HMF) in Human Whole Blood, Clin. Pharmacol. Ther., 2014, 95(1), S83-S84.

7 V. B. Godfrey, L. J. Chen, R. J. Griffin, E. H. Lebetkin and L. T. Burka, Distribution and metabolism of (5-hydroxymethyl)furfural in male F344 rats and B6C3F1 mice after oral administration, J. Toxicol. Environ. Health, Part A, 1999, 57(3), 199-210.
8 D. J. Abraham, A. S. Mehanna, F. C. Wireko, J. Whitney, R. P. Thomas and E. P. Orringer, Vanillin, a potential agent for the treatment of sickle cell anemia, Blood, 1991, 77(6), 1334-1341.

9 S. Park, B. L. Hayes, F. Marankan, D. C. Mulhearn, L. Wanna and A. D. Mesecar, et al., Regioselective Covalent Modification of Hemoglobin in Search of Antisickling Agents, J. Med. Chem., 2003, 46(6), 936-953.

10 A. Nakagawa, F. E. Lui, D. Wassaf, R. Yefidoff-Freedman, D. Casalena and M. A. Palmer, et al., Identification of a Small Molecule that Increases Hemoglobin Oxygen Affinity and Reduces SS Erythrocyte Sickling, ACS Chem. Biol., 2014, 9(10), 2318-2325.

11 A. M. Omar, M. A. Mahran, M. S. Ghatge, N. Chowdhury, F. H. Bamane and M. E. El-Araby, et al., Identification of a novel class of covalent modifiers of hemoglobin as potential antisickling agents, Org. Biomol. Chem., 2015, 13(22), 6353-6370.

12 A. M. Omar, M. A. Mahran, M. S. Ghatge, F. H. A. Bamane, M. H. Ahmed and M. E. El-Araby, et al., Aryloxyalkanoic Acids as Non-Covalent Modifiers of the Allosteric Properties of Hemoglobin, Molecules, 2016, 21(8), 1057.

13 O. Abdulmalik, M. K. Safo, Q. Chen, J. Yang, C. Brugnara and K. Ohene-Frempong, et al., 5-hydroxymethyl-2-furfural modifies intracellular sickle haemoglobin and inhibits sickling of red blood cells, Br. J. Haematol., 2005, 128(4), 552-561.

14 O. Abdulmalik, M. S. Ghatge, F. N. Musayev, A. Parikh, Q. Chen and J. Yang, et al., Crystallographic analysis of human hemoglobin elucidates the structural basis of the potent and dual antisickling activity of pyridyl derivatives of vanillin, Acta Crystallogr., Sect. D: Biol. Crystallogr., 2011, 67(Pt 11), 920-928.

15 A. Parikh, Poster Session II (PII-001-120) Displayed 7:30 am - 3:30 pm Attended 11:45 am - 1:15 pm, Clin. Pharmacol. Ther., 2014, 95, S83-S84.

16 M. K. Safo, O. Abdulmalik, R. Danso-Danquah, J. C. Burnett, S. Nokuri and G. S. Joshi, et al., Structural basis for the potent antisickling effect of a novel class of five-membered heterocyclic aldehydic compounds, J. Med. Chem., 2004, 47(19), 4665-4676.

17 S. M. Shoieb, A. Esmat, A. E. Khalifa and A. B. Abdel-Naim, Chrysin attenuates testosterone-induced benign prostate hyperplasia in rats, Food Chem. Toxicol., 2018, 111, 650-659. 